\title{
AN OBSERVATIONAL STUDY FOR EARLY DETECTION OF INTRAUTERINE GROWTH RESTRICTION IN PREGNANCY USING ULTRASONOGRAPHY AS A TOOL IN FIRST TRIMESTER
}

\author{
Debjani Roy ${ }^{1}$
}

${ }^{1}$ Assistant Professor, Department of Anatomy, IPGME and R, Kolkata, West Bengal.

ABSTRACT
BACKGROUND
In a country like India, Intrauterine Growth Restriction (IUGR) is a serious problem by engulfing a major expenditure for health by
increasing mortality as well as day-to-day morbidity. My intention of this study is to find out IUGR in early trimester upto 13 weeks
of pregnancy, so that we can implement any corrective measures so that rate of IUGR will be minimal and also its adverse
consequences.

\section{MATERIALS AND METHODS}

1120 patients were chosen from an Institute of Infertility Clinic of Kolkata who were free of any medical or surgical problem and conceived by In-Vitro Fertilisation (IVF) due to unexplained infertility having singleton pregnancy. Patient was chosen from IVF, so that exact date of conception can be found to rule out the fallacy of calculating the period of gestation on the basis of menstrual history of patient, which was sometimes approximated. Out of 1120 patients 725 had no clinical pregnancies, rest had undergone ultrasonography. A serial Ultrasonography was done every month and the parameter of crown rump length, femur length, abdominal circumference, head circumference, estimated foetal weight and period of gestation was recorded along with the Amniotic Fluid Index and birth weight (all were delivered by Caesarean Section at 34 - 35 weeks).

\section{RESULTS}

Out of 395 patients, 65 had midterm pregnancy loss; 2 patients delivered IUGR babies, one having history of Oligohydramnios with Oesophageal Atresia and another having Antepartum Haemorrhage with low-lying placenta with anaemia. Four patients were in accordance with normal variant in early trimester become IUGR due to Gestational Diabetes Mellitus (Controlled), Chronic Hypertension. Four patients delivered mild IUGR babies suffering from Nutritional Deficiency because of Morning Sickness (Pyridoxine given) and Hyperprolactinaemia (Bromocriptine given along with amino acid supplement), and 275 patients have positive correlation among CRL and birth weight. Rest 45 mothers had negative correlation having normal CRL, but low birth weight.

\section{CONCLUSION}

Although out of 55 LBW deliveries author found positive correlations only in 10, most of the cases has got negative correlations making the study inconclusive with the hope of scope for further study on adverse effect of procedure of assisted reproductive technique.

\section{KEYWORDS}

Crown-Rump length, Assisted Reproductive Technique, In-Vitro Fertilisation, Intrauterine Growth Restriction.

HOW TO CITE THIS ARTICLE: Roy D. An observational study for early detection of intrauterine growth restriction in pregnancy using ultrasonography as a tool in first trimester. J. Evolution Med. Dent. Sci. 2017;6(53):4012-4016, DOI: 10.14260/Jemds/2017/867

\section{BACKGROUND}

Foetal growth is characterised by sequential pattern of tissue growth, differentiation and maturation. Lein and SantolayaForgas (1998) have classified the phases of growth as that of cellular hyperplasia (conception till 16 weeks), hyperplasia and hypertrophy (16 - 32 weeks) and the last period of hypertrophy only (32 weeks onwards) without any increase in cell number. ${ }^{1}$

Intrauterine Growth Restriction (IUGR) refers to a condition, in which a foetus is unable to achieve its genetically determined potential size. By definition, IUGR is

Financial or Other, Competing Interest: None.

Submission 07-06-2017, Peer Review 25-06-2017,

Acceptance 27-06-2017, Published 03-07-2017.

Corresponding Author:

Dr. Debjani Roy,

Flat No. 2C, $2^{\text {nd }}$ Floor, Sakuntala Apartment,

Kaikhali Ghosh Para,

Kolkata-700052, West Bengal.

E-mail: doctordebjaniroy@gmail.com

DOI: $10.14260 /$ jemds $/ 2017 / 867$ said to be present in those babies whose birth weight is below the $10^{\text {th }}$ percentile of the average for the gestational age. ${ }^{2}$

World Health Organisation (WHO) estimates that globally about 25 million Low-Birth Weight (LBW) babies are born in each year. Among those $2-8 \%$ are born in developed countries and some in developing region (Africa). In fact, South Asia has the highest prevalence of LBW and the latest projection indicates more than half of the world's LBW babies are born here. ${ }^{2}$

In India data collecting from Institutional and community deliveries show wide regional variations of prevalence of LBW from 2.7\% (Madhya Pradesh) and 5.1\% (Assam) to a high of $24.7 \%$ (Tamilnadu) and $40 \%$ (Orissa). ${ }^{3}$

The world summit for children had set a goal of reduction of the LBW prevalence to less than $10 \%{ }^{4}$ associated with a higher rate of multiple births, 5,6 which in turn is associated with LBW. ${ }^{7}$ In addition, studies have suggested that there is a higher rate of low birth weight among singleton infants conceived with assisted reproductive technology than among 
naturally conceived singleton infants ${ }^{8-10}$ or among all infants in the general population. ${ }^{11-15}$

\section{Aims and Objectives}

To correlate the CRL in the first trimester in foetuses conceived by In-Vitro Fertilisation (IVF) with the incidence of IUGR near term or with birth weight that is low for gestational age.

First trimester study for IUGR will be done for earlier monitoring of pregnancy with the hope of best outcome. For accurate prediction of IUGR in first trimester based upon LMP (which is often erroneous), we have taken the help of pregnancy by in-vitro fertilisation.

\section{MATERIALS AND METHODS}

\section{Study Population}

All women who conceived through assisted reproduction (IVF) in the period between September 2008 and August 2010 was recruited for this study.

Author assessed the relationship between discrepancy in the observed and expected size of the foetus in the first trimester and the birth weight, duration of pregnancy and risk of delivering a small for gestational age infant among a large prospective/concurrent cohort of women with a known date of conception. All the relevant data of those patients with IVF pregnancy were collected.

\section{Place of Study}

The data was collected from the Assisted Reproduction Unit, the Obstetrics Unit and the Sonography Unit of one Institute of Reproductive Medicine situated at Salt Lake City, Kolkata.

\section{Inclusion Criteria}

- Maternal age between 19 - 35 years (to exclude agerelated problems on pregnancy).

- Single viable embryo or foetus (conceived by IVF) present when the first ultrasound scan is performed $(9$ 11 weeks of amenorrhoea, because after that frequent movement of embryo may create error in CRL measurement).

\section{Exclusion Criteria}

- A history of rhesus isoimmunisation.

- Essential hypertension.

- Cardiac disease.

- Diabetes mellitus.

- Other medical problems.

- Non-viable embryo or foetus at first scanning.

- Multiple pregnancy (second sac seen on ultrasonography).

- Antenatal detection of foetal abnormality.

- Therapeutic termination of pregnancy.

- Postnatal detection of foetal abnormality.

The above cited cause may affect the growth rate of embryo and the statistical analysis directly or indirectly.

\section{Method of Study}

1120 patients were selected from Institute of Reproductive Medicine, Salt Lake, Kolkata taking prior consent in prescribed form who came with the complaint of pregnancy loss or infertility (primary/secondary).
The patients were divided into two broad groups on the basis of quality of endometrium (by Polymerase chain reaction of endometrium taken by dilatation and curettage of uterus done during pre-conceptional checkup) - (a) Normal endometrium and (b) Abnormal endometrium.

The patient with normal endometrium again was divided on the basis of seminal plasma quality (reactive oxygen status estimation), oocyte quality (from spindle view appearance in meiosis) and embryo quality.

After embryo transfer serial hormonal studies (mainly $\beta$ HCG) was done on ' 0 ' day, $7^{\text {th }}$ day and on $14^{\text {th }}$ day. On and from $6^{\text {th }}$ week, CRL was measured by perabdominal USG.

The scans in the present study was obtained by real-time ultrasonography by using $3.5 \mathrm{MHz}$ transabdominal transducer through a full urinary bladder. Ultrasound was used to measure foetal CRL before 14 weeks (between 59 and 83 days after conception) by the sonographer using electronic calipers on a frozen image on a monitor. The CRL was then to be converted to the equivalent number of days of gestational age on the basis of the formula currently recommended by the British Medical Ultrasound Society for first-trimester estimation of gestational age.

The results of all ultrasound scans obtained were to be entered into a computer database along with details of the women's medical, gynaecologic and obstetrical history, antenatal complications and pregnancy outcome. The difference between the actual and predicted CRL will be expressed as the difference in days of gestation $(\triangle \mathrm{GA})$ - that is the estimated post-conception age according to CRL minus the actual number of days post-conception based on the day of embryo transfer. A negative value indicates a smaller than expected foetus.

Estimated foetal weight (Ultrasonographically) and relevant investigations were done every month.

1120 patients were selected from Institute of Reproductive Medicine, Salt Lake, Kolkata taking prior consent in a prescribed form who came with a complaint of pregnancy loss or infertility (primary/secondary).

Maternal characteristics to be studied were maternal age, height and weight in the first trimester; body mass index; number of previous terms and preterm deliveries, miscarriages and abortions. Complications of pregnancy excluded are preterm delivery, pre-eclampsia, preterm premature rupture of the foetal membranes, preterm labour, placental abruption and placenta previa.

After delivery, Ballard Scoring (birth weight, newborn length, head circumference, abdominal circumference, etc.) were measured to detect whether it is IUGR for the gestational age, which also show negative CRL in early trimester.

Delivery of a small for gestational age infant was defined as birth weight below the $10^{\text {th }}$ percentile for gestational age.

\section{Statistical Analysis}

Statistical Analysis was performed with Statistical Package for the Social Sciences (SPSS Software).

A linear correlation with Pearson ' $r$ ' coefficient has been utilised in a statistical method to calculate the correlation between LBW at delivery with CRL at 9 weeks- 
A. The Odd Ratio between CRL (Positive or Negative), BW at 35 weeks (Normal or low) is 0.00625 . We can calculate ' $p$ ' value from Odd ratio, which is 0.00621 .

B. Rate Ratio $=$ Incidence in LBW with (-) CRL against incidence in LBW with ( + ) CRL $=0.1818$.

C. Risk Ratio $=$ Mother having negative CRL at 9 weeks against mother having positive CRL at 9 weeks $=0.22$ which is $<1$.

D. CRL at 9 weeks True Positive (TP) $=275$, False Positive $(F P)=45$, True Negative $(T N)=10$, so the

E. $\quad$ Specificity $=0.01819$

F. Positive predictive value of USG to detect normal birth weight is 0.859

\section{RESULTS}

1120 patients are taken from an Institute of Infertility Clinic situated at Salt Lake Kolkata, West Bengal who are free of any medical or surgical problems and conceived by In-Vitro Fertilisation (IVF) due to unexplained infertility having singleton pregnancy. Patient was chosen from an IVF, so that exact date of conception can be found to rule out the fallacy of calculating the period of gestation on the basis of menstrual history of patient, which was sometimes approximated. Out of 1120 patients 725 has no clinical pregnancies or pregnancy related complications, rest had undergone ultrasonography.

Out of 395 patients, 65 had midterm pregnancy loss. Two patients delivered IUGR babies, one having history of Oligohydramnios with Oesophageal Atresia and another having Antepartum Haemorrhage with Low-Lying Placenta with Anaemia. Four patients were in accordance with normal variant in early trimester become IUGR due to Gestational Diabetes Mellitus (Controlled) and Chronic Hypertension. Four patients delivered mild IUGR baby suffering from Nutritional Deficiency because of Morning Sickness (Pyridoxine given) and Hyperprolactinaemia (Bromocriptine given along with amino acid supplement), and 275 patients have positive correlation among CRL and birth weight. Rest 45 mothers had negative correlation having normal CRL, but low birth weight.

The outcome of the study has been represented in tabulated form below:

\begin{tabular}{|c|c|}
\hline Result & Birth Weight \\
\hline Normal & 275 \\
\hline IUGR & 55 \\
\hline \multicolumn{2}{|c|}{ Table 1. Final Result of 330 Study Group } \\
\hline
\end{tabular}

Result shows normal birth weight, approximately $91.62 \%$, which is acceptable. It shows IUGR approx. 1.52\%, less than normal suggesting better option of combating IUGR!

\begin{tabular}{|c|c|}
\hline CRL at 9 Weeks & Low Birth Weight \\
\hline Normal value & 45 \\
\hline Negative value & 10 \\
\hline Table 2. Relation of Crown Rump Length with Low Birth \\
Weight
\end{tabular}

Out of 55 deliveries having Low Birth Weight, 10 cases shows negative CRL which is $18.19 \%$.
In contrary, 45 cases showed positive CRL which is $81.12 \%$ which is acceptable hardly.

\begin{tabular}{|c|c|c|c|}
\hline $\begin{array}{c}\text { CRL at 9 } \\
\text { Weeks }\end{array}$ & LBW & In \% & Conclusion \\
\hline $\begin{array}{c}\text { Normal } \\
\text { value }\end{array}$ & 45 & 13.64 & $\begin{array}{c}\text { Not acceptable, contradictory to } \\
\text { general observation } \\
\text { may be due to the effect of IVF }\end{array}$ \\
\hline $\begin{array}{c}\text { Negative } \\
\text { value }\end{array}$ & 10 & 3.03 & Acceptable \\
\hline \multicolumn{3}{|c|}{ Table 3. Correlation of Crown Rump Length with Low } \\
Birth Weight among 330 Samples
\end{tabular}

Out of 55 LBW deliveries, author found negative CRL in 10; most of the cases has got positive CRL making the study inconclusive with the hope of scope for further study on adverse effect of procedure of assisted reproductive technique. So out of 330 patients, 45 although having normal CRL had Low Birth Weight which was about $13.64 \%$ which was significant.

In 10 patients out of 330 had negative CRL having Low Birth Weight, which is about $3.03 \%$ is also significant.

\section{In the Correlation of Negative CRL with LBW}

Pearson ' $r$ ' Coefficient is 0.7457 ; 95\% confidence interval is 0.2186 to 0.9359 ; $P$ value (two tailed) is 0.0133 ; which shows the correlation is significant (alpha=0.05); R square is 0.5561 .

\section{In the Correlation of Positive CRL with LBW}

Pearson ' $r$ ' coefficient is -0.08666 ; 95\% confidence interval is -0.3708 to 0.2123 ; $P$ value (two-tailed) is 0.5714 which shows correlation is not significant; $\mathrm{R}$ square is 0.007510 .

Statistical Analysis was performed with Statistical Package for the Social Sciences (SPSS Software)

\section{DISCUSSION}

LBW (less than $2500 \mathrm{~g}$ ) and birth weight that is low for gestational age are associated with increased perinatal morbidity and mortality, ${ }^{16}$ short- and long-term childhood morbidity and mortality ${ }^{17-18}$ and a range of cardiovascular and metabolic disease in later life. ${ }^{19}$ Consequently, the factors determining birth weight (other than gestational age) are clearly clinically and biologically important. IUGR is aetiologically associated with various maternal, foetal and placental factors, although such an association may not be present in many cases. Maternal factors include hypertensive disease, autoimmune disorders, certain medications, severe malnutrition and maternal lifestyle including smoking, alcohol and cocaine abuse. Foetal aetiologies include aneuploidy, malformation syndrome related to abnormal genomic imprinting, perinatal viral or protozoan infections, preterm birth and multiple gestations. Placental factors may involve many conditions including anatomical, vascular, chromosomal and morphological abnormalities. Also some uterine malformations have been linked to impaired foetal growth.

However, considering a higher incidence of unexplained IUGR at term in singleton babies conceived by assisted reproduction, it remains unclear whether the risk of LBW among this infant is a direct effect of the procedure involving such technology 20,21 or reflects some other factors related to the underlying infertility of the couples who conceive using these procedures. ${ }^{22-24}$ 
It has previously been suggested that variations in foetal size are largely determined in the second half of pregnancy. ${ }^{25}$ However, a single study has shown that foetuses that were smaller than expected in the first trimester (on the basis of menstrual history) were at increased risk of being LBW. ${ }^{26}$ This has been interpreted as indicating that impairment of foetal growth begins in the first trimester.

A 1993 study demonstrated a correlation between firsttrimester crown-rump length and birth weight. ${ }^{27}$ Measurement with ultrasound is recognised to be a more accurate method of estimating gestational age in the first trimester of pregnancy than menstrual dating, owing to errors in the assumed date of conception based on the last menstrual period. With very rapid growth of the foetus during the first trimester- $1 \mathrm{~mm}$ per day at 7 weeks and up to $2 \mathrm{~mm}$ per day by 14 weeks, foetal measurement at this time when correlated with a correctly known gestational age should provide an accurate assessment of foetal growth and any restriction thereof. In women with a certain date of last menstrual period and a regular cycle and in women who conceive through assisted reproductive technology, pregnancies where the Crown-Rump Length (CRL) is smaller than expected may thus be benefited from closer monitoring, especially for abnormalities of foetal growth.

\section{Graph 1 for Correlation of Negative CRL with LBW}

Number of $\mathrm{XY}$ pairs is 10; Pearson ' $r$ ' coefficient is 0.7457; $95 \%$ confidence interval is 0.2186 to 0.9359 ; $P$ value (twotailed) is 0.0133 which shows the correlation is significant (alpha= 0.05); R square is 0.5561 .

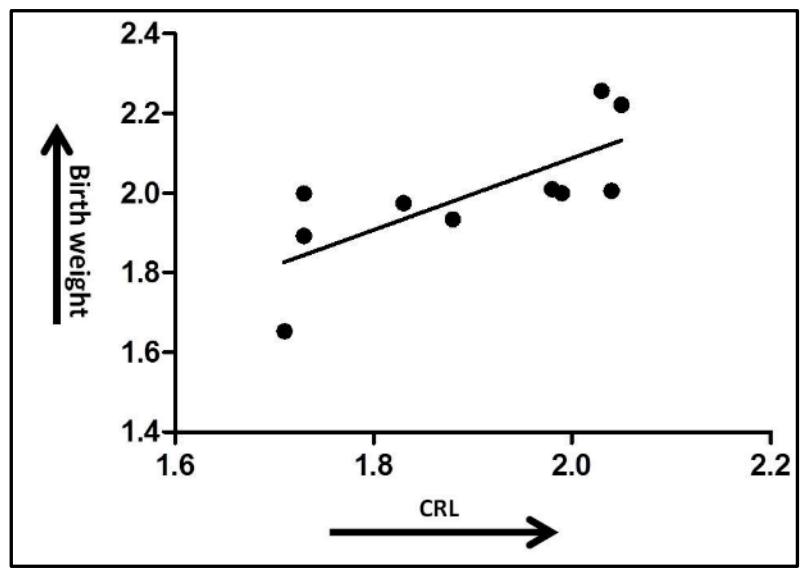

Graph 1. X-Axis: CRL (cm), Y-Axis: BW (kg)

\section{Graph 2 for Correlation of Positive CRL with LBW}

Number of $\mathrm{XY}$ pairs is 45, Pearson ' $r$ ' coefficient is -0.08666 ; $95 \%$ confidence interval is -0.3708 to 0.2123 ; $P$ value (twotailed) is 0.5714 which shows correlation is not significant; $R$ square is 0.007510 .

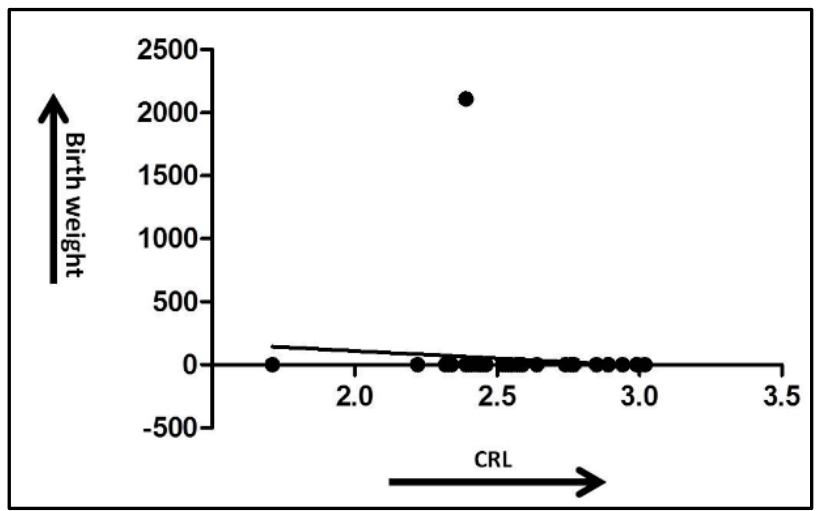

Graph 2. X-Axis: CRL (cm), Y-Axis: BW (kg)

So, Inferences from this Observational Study are-

1. Odd ratio is 0.00625 , which is $<1$ indicating value of CRL has got limited predictive value to ascertain LBW at 35 weeks.

2. The $P$ value, probability of occurrence of positive CRL with the normal BW is 0.00621 which is significant.

3. Rate ratio is $<1$ indicating negative CRL at 9 weeks has got little predictive value for LBW at 35 weeks.

4. Risk ratio is $<1$ indicating negative $\mathrm{CRL}$, not correlating with LBW at 35 weeks.

5. Specificity is 0.01819 , so USG is not a specific diagnostic tool to predict IUGR in early trimester by measuring CRL at least in this study!!

6. Positive predictive value of USG to detect normal birth weight is 0.859 , which is acceptable.

\section{Fallacies of this Study}

1. Although, bias of counting period of Gestation on the basis of IVF can be done easily, but the drawbacks of using chemicals of Artificial Reproductive Techniques cannot be ruled out to project this data in normal population who conceived naturally.

2. Termination of pregnancy by 35 weeks (as the normal procedure of the concerned Institute) by Caesarean Section, author has to restrict herself for estimated foetal weight at 35 weeks and not the actual birth weight at 40 weeks.

\section{ACKNOWLEDGEMENT}

I express my gratitude to Dr. (Prof.) BN Chakraborty, I.R.M Salt Lake, Kolkata for giving scope for this study, constant encouragement and valuable guidance; and thanks to Dr. Arnab Bhattacharya, Assistant Prof., Anatomy, IPGME and R, Kolkata; and Mr. Jaidip Dutta B.C.E for statistical analysis.

\section{REFERENCES}

[1] Cunningham FG, Leveno KJ, Bloom SL. Parturition. In: William's obstetrics. 22 ${ }^{\text {nd }}$ edn. McGraw-Hill, New York, 2005:711-24.

[2] Park K. Park's text books of preventive and social medicine. 18 $8^{\text {th }}$ edn. Banarsidas Bhanot Publishers 2005:1-2.

[3] Ramji S. Birth weight in child survival and safe motherhood programme districts. Personal Communication 1997. 
[4] Nayer D, Kapil U, Saxena N. Nutrient intake and consumption of supplementary nutrition by pregnant mothers in ICDS and non-ICDS areas-a pilot study. Indian pediatr 1997.

[5] Centers for disease control and prevention, American society for reproductive medicine, society for assisted reproductive technology, RESOLVE. 1998 Assisted reproductive technology success rates: national summary and fertility clinic reports, atlanta: centers for disease control and prevention 2000.

[6] Contribution of assisted reproductive technology and ovulation-inducing drugs to triplet and higher-order multiple births- United States, 1980-1997. MMWR Morb Mortal Wkly Rep 2000;49(24):535-8.

[7] Martin JA, Park MM. Trends in twin and triplet births: 1980-1997. National vital statistics reports 1999;47(24)1-20.

[8] Westergaard HB, Johansen AM, Erb K, et al. Danish national in-vitro fertilization registry 1994 and 1995: a controlled study of births, malformations and cytogenetic findings. Hum Reprod 1999;14(7):1896902.

[9] Dhont M, De Sutter P, Ruyssinck G, et al. Perinatal outcome of pregnancies after assisted reproduction: a case-control study. Am J Obstet Gynecol 1999;181(3):688-95.

[10] Verlaenen H, Cammu H, Derde MP, et al. Singleton pregnancy after in vitro fertilization: expectations and outcome. Obstet Gynecol 1995;86(6):906-10.

[11] Bergh T, Ericson A, Hillensjo T, et al. Deliveries and children born after in-vitro fertilization in Sweden 1982-95: a retrospective cohort study. Lancet 1999;354(9190):1579-85.

[12] Pregnancies and births resulting from in vitro fertilization: French national registry, analysis of data 1986 to 1990. FIVNAT (French In Vitro National). Fertil Steril 1995;64(4):746-56.

[13] Gissler M, Silverio MM, Hemminki E. In-vitro fertilization pregnancies and perinatal health in Finland 1991-1993. Hum Reprod 1995;10(7):1856-61.

[14] Friedler S, Mashiach S, Laufer N. Births in Israel resulting form in vitro fertilization/embryo transfer, 1982-1989: national registry of the israeli association for fertility research. Hum Reprod 1992;7(8):1159-63.

[15] Births in Great Britain resulting from assisted conception, 1978-87. MRC Working party on children conceived by in vitro fertilization. BM] 1990;300(6734):1229-33.
[16] Campbell $S$. The detection of intrauterine growth retardation. In: Sharp F, Fraser RB, Milner RD, (eds). RCOG, study group proceedings fetal growth. London. Royal College of Obstetricians and Gynaecologists 1989:251-61.

[17] Buck GM, Cookfair DL, Michalek AM, et al. Intrauterine growth retardation and risk of sudden infant death syndrome. Am J Epidemiol 1989;129(5):874-84.

[18] Holst K, Andersen E, Philip J, et al. Antenatal and perinatal conditions correlated to handicap among 4year-old children. Am J Perinatol 1989;6(2):258-67.

[19] Barker DJ. The fetal and infant origins of adult disease. British Medical Journal 1990;301(6761):1111.

[20] Sundstrom I, IIdgruben A, Hogberg U. Treatmentrelated and treated-independent deliveries among infertile couples, a long-term follow-up. Acta Obstet Gynecol Scand 1997;76(3):238-43.

[21] Olivennes F, Rufat P, Andre B, et al. The increased risk of complication observed in singleton pregnancies resulting from in-vitro fertilization (IVF) does not seem to be related to the IVF method itself. Hum Reprod 1993;8(8):1297-300.

[22] Henriksen TB, Baird DD, Olsen J, et al. Time to pregnancy and preterm delivery. Obstet Gynecol 1997;89(4):594-9.

[23] Williams MA, Goldman MB, Mittendorf $R$, et al Subfertility and the risk of low birth weight. Fertil Steril 1991;56(4):668-71.

[24] McElrath TF, Wise PH. Fertility therapy and the risk of very low birth weight. Obstet Gynecol 1997;90(4 Pt 1):600-5.

[25] Gluckman PD, Liggins GC. Regulation of fetal growth. In: Beard RW, Nathanielz PW, (eds). Fetal physiology and medicine: the basis of perinatology. $2^{\text {nd }}$ edn. Rev. Vol: 6 of reproductive medicine. New York: Marcel Dekker 1984:511-58.

[26] Smith GC, Smith MF, McNay MB, et al. First-trimester growth and the risk of low birth weight. N Engl J Med 1998;339(25):1817-22.

[27] Dickey RP, Gasser RF. Ultrasound evidence for variability in the size and development of normal human embryos before the tenth post-insemination week after assisted reproductive technologies. Hum Reprod 1993;8(2):331-7. 